\title{
Faktor Risiko Kematian Ibu
}

\author{
Risk Factors of Maternal Mortality
}

\section{Nurul Aeni}

\author{
Kantor Penelitian dan Pengembangan Kabupaten Pati
}

\begin{abstract}
Abstrak
Angka Kematian Ibu (AKI) di Kabupaten Pati bergerak fluktuatif dan menunjukkan status tertinggi pada tahun 2011 dengan 126 per $100.000 \mathrm{ke}$ lahiran hidup. Tujuan penelitian ini adalah menggambarkan kematian ibu di Kabupaten Pati dan menganalisis faktor risiko kematian maternal di Kabupaten Pati Tahun 2011. Penelitian menggunakan pendekatan observasional analitik dengan metode kasus kontrol. Jumlah sampel adalah 24 untuk setiap kelompok kasus dan kelompok kontrol. Analisis data menggunakan uji univariat, bivariat dan multivariat. Hasil dari penelitian adalah tiga penyebab utama kematian ibu di Kabupaten Pati adalah penyakit jantung, preeklamsi/eklamsi, dan perdarahan. Kematian ibu tersebar di 16 kecamatan dari 21 kecamatan yang ada dan sebagian besar kematian terjadi pada masa nifas. Analisis regresi logistik menunjukkan bahwa faktor yang berpengaruh terhadap kematian ibu adalah komplikasi kehamilan (OR $=12,198$, nilai $p=0,010)$, komplikasi persalinan $(O R=9,94$, nilai $p=0,020)$ dan riwayat penyakit $(O R=27,735$, nilai $p=0,011)$. Secara bersama-sama, ketiga variabel tersebut berkontribusi terhadap 64,3\% kematian ibu yang terjadi di Kabupaten Pati Tahun 2011.
\end{abstract}

Kata kunci: kematian ibu, komplikasi kehamilan, komplikasi persalinan

\footnotetext{
Abstract

Maternal Mortality Ratio (MMR) of Pati Regency fluctuated and showed the highest state in 2011 with 126 per 100.000 live births. This research aimed to describe maternal mortality cases in Pati Regency and to analyze risk factors of maternal mortality happened in 2011. This research used observational analysis, i.e. cases control study. The number of samples was 24 in each of case group and control group. Data was analyzed with univariate, bivariate, and multivariate. This research resulted that three major causes of maternal mortality were heart disease, preeclampsia/eclampsia, and hemorrhage. Maternal mortality spread on 16 from 21 sub-districts on Pati Regency and the majority of them happened in post delivery period. Logistic regression analysis concluded that risk factors influenced maternal
}

mortality were pregnancy complication $(O R=12.198$, p value $=0.010)$, delivery complication $(O R=9.94$, $p$ value $=0.020)$ and history of illness $(O R$ $=27.735, p$ value $=0.011$ ). Collectively, those variables contributed to $64.3 \%$ of maternal mortality in Pati Regency 2011.

Keywords: Maternal mortality, pregnancy complication, delivery complication

\section{Pendahuluan}

Setiap tahun, di seluruh dunia, diperkirakan terjadi 358.000 kematian ibu dan sekitar 99\% kematian tersebut terjadi di negara berkembang yang miskin dan sekitar 67\% merupakan sumbangan sebelas negara temasuk Indonesia. ${ }^{1}$ Angka Kematian Ibu (AKI) di Indonesia pada tahun 2007 adalah 228 per 100.000 kelahiran hidup sehingga hampir dapat dipastikan bahwa Indonesia tidak akan mampu mencapai target Millenium Development Goals, menurunkan AKI menjadi 102 per 100.000 kelahiran hidup pada tahun $2015 .^{2}$

Kematian ibu merupakan peristiwa kompleks yang disebabkan oleh berbagai penyebab yang dapat dibedakan atas determinan dekat, antara, dan jauh. ${ }^{3}$ Determinan dekat yang berhubungan langsung dengan kematian ibu merupakan gangguan obstetrik seperti perdarahan, preeklamsi/eklamsi, dan infeks atau penyakit yang diderita ibu sebelum atau selama kehamilan yang dapat memperburuk kondisi kehamilan seperti jantung, malaria, tuberkulosis, ginjal, dan acquired immunodeficiency syndrome. Determinan dekat secara langsung

Alamat Korespondensi: Nurul Aeni, Kantor Penelitian dan Pengembangan Kabupaten Pati, Jl. P. Sudirman No. 26 Pati, Hp. 08562798734, e-mail: aeni_240884@yahoo.co.id 
dipengaruhi oleh determinan antara yang berhubungan dengan faktor kesehatan, seperti status kesehatan ibu, status reproduksi, akses terhadap pelayanan kesehatan, dan perilaku penggunaan fasilitas kesehatan. Determinan jauh berhubungan dengan faktor demografi dan sosiokultural. Kesadaran masyarakat yang rendah tentang kesehatan ibu hamil, pemberdayaan perempuan yang tidak baik, latar belakang pendidikan, sosial ekonomi keluarga, lingkungan masyarakat dan politik, serta kebijakan secara tidak langsung diduga ikut berperan dalam meningkatkan kematian ibu. ${ }^{4}$

AKI yang tinggi di suatu wilayah pada dasarnya menggambarkan derajat kesehatan masyarakat yang rendah dan berpotensi menyebabkan kemunduran ekonomi dan sosial di level rumah tangga, komunitas, dan nasional. Namun, dampak terbesar kematian ibu yang berupa penurunan kualitas hidup bayi dan anak menyebabkan goncangan dalam keluarga dan selanjutnya memengaruhi tumbuh kembang anak. ${ }^{5}$ Untuk menurunkan AKI, Kementerian Kesehatan Republik Indonesia mencanangkan Making Pregnancy Safer (MPS), antara lain terimplementasi dalam program Jampersal untuk menjamin semua persalinan dilakukan di fasilitas kesehatan dan oleh tenaga kesehatan terlatih serta penyediaan pelayanan obstetri neonatal emergensi dasar (PONED) dan pelayanan obstetri neonatal emergensi komprehensif (PONEK) untuk menjamin semua komplikasi obstetrik dapat tertangani dengan optimal. Selain itu, Kementerian Negara Pemberdayaan Perempuan juga mencanangkan Gerakan Sayang Ibu (GSI) sebagai upaya menumbuhkan kesadaran bahwa kehamilan dan kelahiran dapat memunculkan risiko dan tidak hanya menjadi tanggung jawab ibu, tetapi juga juga keluarga, suami, orang tua, dan masyarakat. ${ }^{6}$

Meskipun banyak usaha yang telah dilakukan untuk mengurangi kematian ibu, sejumlah wilayah di Indonesia masih mempunyai AKI tinggi. Jumlah kematian ibu terbanyak justru terjadi di provinsi dengan AKI rendah dan cakupan persalinan dengan tenaga kesehatan tinggi, seperti Jawa Barat, Jawa Timur dan Jawa Tengah. Di Jawa Tengah, tahun 2011, AKI adalah 116 per 100.000 kelahiran hidup dengan persebaran yang menunjukkan beberapa kabupaten mempunyai AKI lebih tinggi Jawa Tengah dan nasional, salah satu adalah Kabupaten Pati. ${ }^{7}$ Data Dinas Kesehatan Kabupaten Pati menyatakan bahwa sejak tahun 2009 AKI di Kabupaten Pati berfluktuatif dan cenderung meningkat dan mencapai puncak pada tahun 2011 dengan AKI sebesar 126 per 100.00 kelahiran hidup.

Keragaman wilayah, karakteristik demografi, dan sumber daya hendaknya menjadi pertimbangan untuk merencanakan program penurunan AKI. Agar setiap program yang dicanangkan berjalan efektif, setiap wilayah membutuhkan pendekatan yang berbeda. Untuk itu, perlu dilakukan kajian guna menemukan faktor penyebab kematian ibu sebagai bahan masukan bagi pemerintah daerah dalam upaya menurunkan angka kematian ibu. Tujuan penelitian ini adalah menggambarkan kematian ibu yang terjadi di Kabupaten Pati tahun 2011 dan menganalisis determinan kematian ibu yang meliputi determinan dekat, determinan antara, dan determinan jauh.

\section{Metode}

Penelitian observasional analitik ini menggunakan desain studi kasus kontrol. Kelompok kasus adalah seluruh kasus kematian ibu yang terjadi pada tahun 2011, di Kabupaten Pati, kelompok kontrol adalah ibu yang berdomisili di desa yang sama dengan ibu yang mengalami kematian yang melahirkan dan mempunyai usia kehamilan atau waktu persalinan yang berdekatan. Populasi penelitian adalah ibu yang hamil di Kabupaten Pati pada tahun 2011 dan sampel penelitian meliputi kasus dan sampel kontrol dengan jumlah sama besar masing-masing adalah 24 ibu. Penelitian ini menggunakan sumber data primer dari hasil wawancara dan observasi terhadap keluarga ibu yang mengalami kematian. Untuk kelompok kontrol, wawancara dilakukan pada bidan desa dan bidan yang membantu persalinan. Data sekunder berupa data kematian ibu didapat dari Dinas Kesehatan Kabupaten Pati, catatan pemeriksaan kehamilan ibu (KMS), otopsi verbal maternal (OVM), serta literatur yang relevan.

Metode analisis yang digunakan meliputi analisis univariat, bivariat dengan uji kai kadrat, dan analisis multivariat melalui regresi logistik linear. Variabel yang dinyatakan masuk dalam model multivariat adalah variabel yang pada ujian bivariat mempunyai nilai $\mathrm{p}<0,25$. Penentuan model regresi logistik dilakukan secara bertahap. Variabel yang sesuai untuk model adalah variabel yang mempunyai nilai $p<0,05$, sehingga variabel yang tidak memenuhi kriteria nilai dikeluarkan dari model. Untuk menguji apakah model yang dihasilkan sesuai dengan data empiris dilakukan analisis ketepatan model dengan melihat nilai Homer and Lemeshow Test. Model dapat diterima apabila nilai Homer dan Lemeshow Test mempunyai signifikansi $>0,05$.

\section{Hasil}

Kematian ibu di Kabupaten Pati memiliki penyebab yang beragam, baik penyebab langsung maupun penyebab tidak langsung. Rangkuman penyebab kematian ibu di Kabupaten Pati ditampilkan dalam Tabel 1.

Proporsi ibu yang mengalami komplikasi kehamilan, persalinan, dan nifas pada kelompok kasus lebih tinggi yang tidak terjadi pada determinan antara, proporsi pada kelompok kontrol lebih tinggi daripada kelompok kasus, meliputi status gizi dan paritas. Pada variabel status 
Tabel 1. Kategori Penyebab Kematian Ibu

\begin{tabular}{llcc}
\hline Penyebab Kematian & Kategori & Jumlah & Persentase (\%) \\
\hline Penyebab langsung & Atona uteri & 1 & 4,2 \\
& Perdarahan & 3 & 12,5 \\
& Preeklamsi/eklamsi & 1 & 4,2 \\
& Infeksi & 7 & 29,1 \\
& Kehamilan ektopik terganggu & 1 & 4,2 \\
& Abortus & 1 & 4,2 \\
Penyebab tidak langsung & Retentio urine & 1 & 4,2 \\
& Penyakit jantung & 8 & 33,1 \\
\hline Total & & 24 & 100,0 \\
\hline
\end{tabular}

anemia, jarak kehamilan, penolong persalinan, cara persalinan, dan keterlambatan rujukan. Jumlah sampel pada kelompok kasus dan kelompok kontrol tidak sama. Pada variabel status anemia, sebanyak $15 \mathrm{ibu}$ pada kelompok kasus dan 17 ibu pada kelompok kontrol tidak mempunyai data status anemia pada saat kehamilan. Pada variabel Jarak Kehamilan, sebanyak sembilan ibu pada kelompok kasus dan delapan ibu pada kelompok kontrol merupakan primigravid. Pada variabel penolong persalinan dan cara persalinan, sebanyak delapan ibu pada kelompok kasus meninggal pada masa kehamilan sehingga tidak mengalami persalinan, dan pada variabel keterlambatan rujukan, sebanyak 16 ibu pada kelompok kontrol tidak mengalami gangguan obstetrik sehingga tidak perlu dirujuk. Untuk variabel pada determinan jauh, proporsi faktor risiko kematian ibu pada kelompok kasus sama dengan proporsi pada kelompok kontrol, kecuali variabel pendapatan, proporsi kematian ibu pada kelompok kontrol lebih tinggi daripada kelompok kasus (Tabel 2).

Analisis bivariat menggunakan uji kai kuadrat untuk menentukan variabel yang akan disertakan dalam model. Terdapat 10 variabel yang memenuhi kriteria untuk diikutkan dalam analisis multivariat, yaitu komplikasi kehamilan, komplikasi persalinan, komplikasi nifas, status gizi, status anemia, riwayat penyakit, usia ibu hamil, pemeriksaan antenatal, cara persalinan, dan keterlambatan rujukan (Tabel 3).

Model regresi logistik yang dihasilkan memuat tiga variabel yaitu komplikasi kehamilan, komplikasi persalinan, dan riwayat penyakit. Pengujian permodelan juga membuktikan keberdaan interaksi. Model yang dihasilkan adalah model tanpa interaksi. Signifikansi Homer and Lemeshow Test adalah > 0,05 menunjukkan model yang dihipotesiskan sesuai dengan data empiris atau dengan kata lain model dapat diterima. Variabilitas variabel dependen yang dapat dijelaskan variabel independen ditunjukkan melalui nilai Nagelkerke $R^{2}$ $(0,643)$ yang berarti variabel independen yang sesuai dengan model berpengaruh $64,3 \%$ terhadap variabilitas variabel dependen. Sedangkan, pada tabel klasifikasi menunjukkan persentase $83,3 \%$, yang berarti ketepatan prediksi model yang dihasilkan dibandingkan data empiris adalah sekitar 83,3\% (Tabel 4).

Analisis parsial menguji variabel bebas yang berpengaruh terhadap variabel terikat dengan menggunakan uji statistik Wald. Komplikasi kehamilan, komplikasi persalinan, dan riwayat penyakit berpengaruh terhadap kematian ibu. Komplikasi kehamilan berpengaruh terhadap kematian ibu dengan odds ratio (OR) sebesar 12,189 (nilai $\mathrm{p}=0,01$; CI 95\% $=1,819-81,817$ ). Apabila variabel komplikasi persalinan dan riwayat penyakit dibuat konstan (dikontrol), ibu yang mengalami komplikasi kehamilan berisiko mengalami kematian 12,198 kali lebih besar daripada ibu yang tidak mengalami komplikasi kehamilan. Komplikasi persalinan berpengaruh terhadap kematian ibu dengan OR sebesar 9,94 (nilai $\mathrm{p}=0,02$; CI 95\% $=1,44-68,59$ ). Apabila variabel komplikasi kehamilan dan riwayat penyakit dibuat konstan (dikontrol), ibu yang mengalami komplikasi persalinan berisiko 9,94 kali lebih besar untuki mati daripada ibu yang tidak mengalami komplikasi persalinan. Variabel riwayat penyakit berpengaruh terhadap kematian ibu dengan OR sebesar 27,735 (nilai $\mathrm{p}=0,011$; CI $95 \%=2,118-363,147)$. Apabila komplikasi kehamilan dan komplikasi persalinan dibuat konstan (dikontrol), ibu yang mempunyai riwayat penyakit sebelum kehamilan, mempunyai risiko 27,74 kali lebih besar untuk mengalami kematian daripada ibu yang tidak memikili riwayat penyakit (Tabel 5).

\section{Pembahasan}

\section{Gambaran Kematian Ibu}

Kematian ibu di Kabupaten Pati Tahun 2011 paling banyak disebabkan oleh penyakit jantung, preeklamsi/ eklamsi, dan perdarahan. Hasil tersebut berbeda dengan hasil Survei Kesehatan Rumah Tangga (SKRT) tahun 2007 yang menemukan tiga penyebab utama kematian ibu di Indonesia adalah perdarahan, preeklamsi/eklamsi, dan Infeksi. ${ }^{2}$ Berdasarkan sebaran pada tahun 2011, ke- 
Tabel 2. Proporsi Faktor Risiko Kematian Ibu

\begin{tabular}{|c|c|c|c|c|c|}
\hline \multirow[t]{2}{*}{ Variabel Independen } & \multirow[t]{2}{*}{ Kategori } & \multicolumn{2}{|c|}{ Kasus } & \multicolumn{2}{|c|}{ Kontrol } \\
\hline & & $\mathrm{n}$ & $(\%)$ & $\mathbf{n}$ & $(\%)$ \\
\hline \multicolumn{6}{|l|}{ Determinan dekat } \\
\hline \multirow[t]{2}{*}{ Komplikasi kehamilan } & Mengalami & 17 & 70,8 & 3 & 12,5 \\
\hline & Tidak & 7 & 29,2 & 21 & 87,5 \\
\hline \multirow[t]{2}{*}{ Komplikasi persalinan } & Mengalami & 12 & 50,0 & 5 & 20,8 \\
\hline & Tidak & 12 & 50,0 & 19 & 79,2 \\
\hline \multirow{2}{*}{ Komplikasi nifas } & Mengalami & 10 & 41,7 & 0 & 0 \\
\hline & Tidak & 14 & 58,3 & 24 & 100 \\
\hline \multicolumn{6}{|l|}{ Determinan antara } \\
\hline \multirow{2}{*}{ Status gizi } & Kekurangan energi kronik & 3 & 12,5 & 4 & 16,7 \\
\hline & Tidak & 21 & 87,5 & 20 & 83,3 \\
\hline \multirow[t]{2}{*}{ Status anemia } & Anemia & 7 & 77,8 & 3 & 42,9 \\
\hline & Tidak & 2 & 22,2 & 4 & 57,1 \\
\hline \multirow[t]{2}{*}{ Riwayat penyakit } & Mempunyai & 13 & 54,2 & 1 & 4,2 \\
\hline & Tidak & 11 & 45,8 & 23 & 95,8 \\
\hline \multirow[t]{2}{*}{ Usia ibu hamil } & Berisiko $(<20,>35$ tahun $)$ & 9 & 37,5 & 4 & 16,7 \\
\hline & Tidak (20-35 tahun) & 15 & 62,5 & 20 & 83,3 \\
\hline \multirow[t]{2}{*}{ Paritas } & Berisiko $(\leq 1,>4)$ & 10 & 41,7 & 11 & 45,8 \\
\hline & Tidak (2-4) & 14 & 58,3 & 13 & 54,2 \\
\hline \multirow[t]{2}{*}{ Jarak kehamilan } & Berisiko $(<2$ tahun $)$ & 3 & 20 & 3 & 18,8 \\
\hline & Tidak (> 2 tahun) & 12 & 80 & 13 & 81,2 \\
\hline \multirow[t]{2}{*}{ Periksa antenatal } & Tidak baik $(<4$ kali) & 10 & 41,7 & 2 & 8,3 \\
\hline & Baik ( $\geq 4$ kali) & 14 & 58,3 & 22 & 91,7 \\
\hline \multirow[t]{2}{*}{ Penolong persalinan } & Nontenaga kesehatan & 2 & 12,5 & 1 & 4,2 \\
\hline & Tenaga kesehatan & 14 & 87,5 & 23 & 95,8 \\
\hline \multirow[t]{2}{*}{ Cara persalinan } & Tindakan & 9 & 56,2 & 6 & 25,0 \\
\hline & Spontan & 7 & 43,8 & 18 & 75,0 \\
\hline \multirow[t]{2}{*}{ Keterlambatan rujukan } & Terlambat & 20 & 83,3 & 2 & 20,0 \\
\hline & Tidak terlambat & 4 & 16,7 & 4 & 80,0 \\
\hline \multicolumn{6}{|l|}{ Determinan Jauh } \\
\hline \multirow{2}{*}{ Pendidikan ibu } & $\leq \mathrm{SMP}$ & 16 & 66,7 & 16 & 66,7 \\
\hline & $\geq$ SMA & 8 & 33,3 & 8 & 33,3 \\
\hline \multirow{2}{*}{ Status pekerjaan } & Bekerja & 6 & 25,0 & 6 & 25,0 \\
\hline & Tidak bekerja & 18 & 75,0 & 18 & 75,0 \\
\hline \multirow[t]{2}{*}{ Pendapatan } & $\leq 1$ juta & 6 & 25,0 & 9 & 37,5 \\
\hline & $>1$ juta & 18 & 75,0 & 15 & 62,5 \\
\hline
\end{tabular}

matian ibu terjadi di 16 kecamatan dari 21 kecamatan yang ada di Kabupaten Pati, dengan kematian terbanyak terjadi di Kecamatan Tlogowungu dan Sukolilo.

Berdasarkan waktu kejadian, kematian ibu paling banyak terjadi pada masa nifas hingga 42 hari setelah persalinan. Di Jawa Tengah, tahun 2010 lebih dari setengah kematian ibu terjadi pada masa nifas. ${ }^{8}$ Pada penelitian ini, sekitar $40 \%$ kematian ibu masa nifas terjadi beberapa jam setelah persalinan. Kondisi ini mengindikasikan mekanisme pengawasan setelah persalinan oleh tenaga medis yang masih lemah. Oleh sebab itu, Dinas Kesehatan Kabupaten Pati menginstruksikan kepada para bidan untuk melakukan persalinan empat tangan (penanganan persalinan oleh dua bidan), agar kondisi ibu dan bayi setelah melahirkan tetap terpantau, tetapi anjuran tersebut belum sepenuhnya dilaksanakan.

Selain itu, faktor budaya dan tradisi masih berperan dalam proses perawatan masa nifas melalui pengaruh keluarga yang berperan dalam perawatan pascamelahirkan. Sebagian dari praktik tersebut adalah pan- tangan dan atau keharusan untuk mengonsumsi makanan tertentu. Pada masa nifas, ibu hanya mengonsumsi nasi putih tanpa protein hewani dan membatasi konsumsi air putih karena dianggap dapat memperlambat proses penyembuhan luka. Hal tersebut dapat menurunkan kondisi ibu pascamelahirkan yang membutuhkan cukup asupan gizi untuk mengembalikan kondisi tubuh dan membantu proses menyusui. 9,10

\section{Determinan Dekat}

Determinan dekat yang berpengaruh terhadap kematian ibu adalah komplikasi kehamilan dan persalinan, sedangkan komplikasi nifas tidak. Komplikasi kehamilan secara signifikan berpengaruh terhadap kematian ibu $(\mathrm{OR}=12,198$; nilai $\mathrm{p}=0,010 ; 95 \% \mathrm{CI}=1,819-$ 81,817). Di Kabupaten Cilacap dan RSU Dr Mohammad Hoesin, komplikasi persalinan berisiko kematian ibu 147,1 kali lebih besar (nilai $\mathrm{p}=0,002$ ) dan 5,5 (nilai $\mathrm{p}=$ 0,001). ${ }^{11,12}$ Komplikasi kehamilan yang paling banyak pada penelitian ini adalah adalah preeklamsi/eklamsi. 
Tabel 3. Hasil Analisis Bivariat

\begin{tabular}{|c|c|c|c|}
\hline Variabel Independen & OR & CI 95\% & Nilai $p$ \\
\hline \multicolumn{4}{|l|}{ Determinan Dekat } \\
\hline Komplikasi kehamilan & 17,0 & $3,81-75,87$ & 0,000 \\
\hline Komplikasi persalinan & 3,8 & $1,07-13,52$ & 0,035 \\
\hline Komplikasi nifas & 35,48 & - & 0,000 \\
\hline \multicolumn{4}{|l|}{ Determinan Antara } \\
\hline Status gizi & 0,71 & $0,14-3,6$ & 0,155 \\
\hline Status anemia & 4,6 & $0,44-48,47$ & 0,172 \\
\hline Riwayat penyakit & 27,18 & $3,14-235,02$ & 0,000 \\
\hline Usia ibu hamil & 3 & $0,78-11,63$ & 0,104 \\
\hline Paritas & 0,84 & $0,27-2,64$ & 0,771 \\
\hline Jarak kehamilan & 1,08 & $0,18-6,44$ & 0,930 \\
\hline Pemeriksaan antenatal & 7,86 & $1,49-41,3$ & 0,008 \\
\hline Penolong persalinan & 3,29 & $0,27-39,66$ & 0,327 \\
\hline Cara persalinan & 3,86 & $1,00-14,92$ & 0,046 \\
\hline Keterlambatan rujukan & 10,0 & $1,34-74,5$ & 0,013 \\
\hline \multicolumn{4}{|l|}{ Determinan Jauh } \\
\hline Pendidikan ibu & 1,00 & $0,30-3,32$ & 1,000 \\
\hline Status pekerjaan & 1,00 & $0,27-3,69$ & 1,000 \\
\hline Pendapatan keluarga & 0,56 & $0,16-1,92$ & 0,350 \\
\hline
\end{tabular}

Tabel. 4. Hasil Pengujian Model Regresi Logistik

\begin{tabular}{lc}
\hline Hasil Pengujian & Nilai \\
\hline Homer and lemeshow test & $\mathrm{X}^{2}=1,540 ;$ Nilai $\mathrm{p}=0,819$ \\
Model summary (Nagelkerke $\mathrm{R}^{2}$ ) & 0,643 \\
Classification table (Overall percentage) & 83,3 \\
\hline
\end{tabular}

Tabel 5. Model Akhir Logistik Regresi Ganda

\begin{tabular}{lllll}
\hline Variabel & B & Nilai p & OR & CI 95\% \\
\hline Komplikasi kehamilan & 2,501 & 0,010 & 12,198 & $1,819-81,817$ \\
Komplikasi persalinan & 2,297 & 0,020 & 9,94 & $1,441-68,592$ \\
Riwayat penyakit & 3,323 & 0,011 & 27,735 & $2,118-363,147$ \\
Konstanta & $-5,573$ & 0,001 & & \\
\hline
\end{tabular}

Beberapa faktor yang berpotensi meningkatkan prevalensi preeklamsi/eklamsi adalah kehamilan pertama kali (primigravida), riwayat penyakit sebelum kehamilan (penyakit ginjal dan tekanan darah tinggi), kehamilan dengan regangan rahim makin tinggi (hamil dengan kebanyakan air ketuban, kehamilan ganda, dan hamil dengan janin besar). ${ }^{13}$ Observasi prevalensi preeklamsi/ eklamsi pada kelompok kasus menemukan sebagian besar sampel hamil pada usia $>35$ tahun yang berisiko. Penelitian di Finlandia, perempuan yang hamil pada usia lebih dari 35 tahun berpeluang 1,5 kali lebih besar mengalami preeklamsi daripada ibu hamil berusia di bawah 35 tahun. ${ }^{14}$

Komplikasi persalinan berkontribusi terhadap kematian ibu dengan menyumbang risiko 9,94 kali (nilai $\mathrm{p}$ $=0,020,95 \% \mathrm{CI}=1,441-68,592)$. Hasil penelitian ini sejalan dengan penelitian kematian ibu di Kabupaten Cilacap dengan dengan OR sebesar 49,2 dan nilai $\mathrm{p}=$ 0,027 dan penelitian di Rumah Sakit Umum Dr.
Mohammad Hoesin Palembang dengan OR sebesar 8,50 dan nilai $\mathrm{p}=0,001) .{ }^{11,12}$ Analisis univariat menunjukkan bahwa jenis komplikasi persalinan didominasi oleh preeklamsi/eklamsi $(29,4 \%)$ dan perdarahan $(23,53 \%)$. Jenis perdarahan yang paling dominan adalah atonia uteri yang secara teoritis berhubungan dengan anemia pada masa kehamilan. Namun, prevalensi anemia tidak diketahui karena tidak semua sampel melakukan uji hemoglobin pada masa kehamilan. Atonea uteri juga dapat disebabkan penangan kala III persalinan yang salah, dengan memijat dan mendorong uterus ke bawah untuk melahirkan plasenta. Oleh sebab itu, tenaga persalinan yang berkompeten mutlak diperlukan untuk menjamin persalinan yang aman. ${ }^{15}$

Untuk menjamin persalinan yang aman, pemerintah Kabupaten Pati mengadakan pelatihan Acuan Persalinan Normal (APN) bagi para bidan. Pelaksanaan pelatihan APN di Kabupaten Pati menghadapi kendala jumlah peserta pada setiap pelaksanaan terbatas, mengingat prioritas keikutsertaan diberikan kepada bidan pegawai negeri sipil (PNS) senior sehingga bidan desa yang sebagian besar merupakan bidan pegawai tidak tetap (PTT) belum mengikuti pelatihan APN. Berdasarkan data dari Dinas Kesehatan Kabupaten Pati, hingga bulan Maret 2012, jumlah bidan desa yang belum menerima pelatihan APN adalah 172 bidan atau mencapai 40,95\% dari jumlah seluruh bidan, dan sekitar 95,34\% jumlah tersebut merupakan bidan PTT dengan masa kerja yang masih rendah.

\section{Determinan Antara}

Ada empat dari 10 determinan antara yang dalam analisis bivariat berhubungan bermakna dengan kematian ibu meliputi riwayat penyakit, pemeriksaan antenatal, cara persalinan, dan keterlambatan rujukan. Namun, pada model multivariat, hanya riwayat penyakit yang berpengaruh terhadap kematian ibu, yaitu riwayat penyakit. Riwayat penyakit meningkatkan risiko kematian ibu sekitar 27,74 kali lebih besar (nilai $\mathrm{p}=0,011$, $95 \%$ CI $=1,118-363,147)$. Hasil tersebut sesuai dengan penelitian di Kabupaten Cilacap $(\mathrm{OR}=210$, 2; nilai $\mathrm{p}=0,002)$ dan penelitian di Rumah Sakit Umum Mohammad Hoesin Palembang $(\mathrm{OR}=4,4$; nilai $\mathrm{p}=$ 0,001). ${ }^{11,12}$ Kematian ibu akibat penyakit yang diderita sebelum kehamilan pada dasarnya dapat dicegah dengan melakukan deteksi sejak dini. Hal tersebut tampaknya belum menjadi perhatian tenaga kesehatan yang melakukan pemeriksaan antenatal. Observasi buku pemeriksaan kehamilan (KMS) pada kelompok kasus menemukan hampir seluruhnya tidak menyantumkan riwayat penyakit. Dari wawancara dengan keluarga dan observasi OVM diketahui bahwa ibu mempunyai riwayat penyakit sebelum kehamilan.

Riwayat penyakit yang paling banyak diderita adalah 
penyakit jantung yang rentan mengalami komplikasi jantung berupa aritmia dan gagal jantung, dan komplikasi obstetrik seperti preeklamsi, serta komplikasi neonatal seperti kelahiran prematur dan kematian bayi. ${ }^{16}$ Pada kehamilan 34 - 36 minggu, terjadi peningkatan aktivitas jantung yang ditandai dengan peningkatan frekuensi denyut jantung dan nadi rata-rata 88 kali permenit. Pada jantung normal tidak menjadi masalah, tetapi pada ibu dengan penyakit jantung, dapat menyebabkan decompensasi cordis.

Pemeriksaan antenatal yang tidak baik dan tidak lengkap meningkatkan risiko kematian ibu hingga 7,86 kali (nilai $\mathrm{p}=0,008$; CI 95\% $=1,49-41,3$ ). Di Kabupaten Bulukumba, tahun 2007 - 2009, ibu yang tidak melakukan pemeriksaan antenatal dengan teratur atau $<4$ kali berisiko kematian 4,57 kali lebih besar daripada ibu yang teratur melakukan pemeriksaan antenatal. ${ }^{17}$ Sedangkan, penelitian di Provinsi Sumatera Selatan, ibu yang tidak pernah atau kurang dari 4 kali memeriksakan kehamilan/antenatal care berisiko kematian 3,5 kali lebih besar daripada ibu yang memeriksakan kehamilan $\geq 4$ kali. $^{18}$ Namun, pemeriksaan kehamilan yang baik dan berkualitas hanya dapat diberikan oleh tenaga kesehatan yang berkualitas yang tidak hanya diukur dari kemampuan teknis dan fasilitas yang dimiliki, melainkan juga perhatian dan pandangan petugas kesehatan terhadap masalah pelayanan kebidanan di masyarakat, mulai dari pengenalan masalah, usaha meningkatkan kualitas kesehatan, dan upaya pencegahan penyakit yang menjadi masalah. ${ }^{19}$ Pada penelitian ini, ibu hamil kelompok kasus dan kelompok kontrol memilih memeriksakan kehamilan di Bidan Praktek Swasta (BPS) daripada bidan desa karena dianggap lebih berpengalaman dan kompeten. Sekitar $64,34 \%$ bidan desa merupakan bidan honorer dengan masa kerja yang kurang dari $<5$ tahun.

Variabel persalinan dengan tindakan berpengaruh terhadap kematian ibu $(\mathrm{OR}=3,86$; nilai $\mathrm{p}=0,046$, CI 95\% $=1,21-19,71)$ berarti berisiko kematian 3,86 kali lebih besar daripada persalinan normal. Cara persalinan dengan tindakan yang berisiko menyebabkan kematian antara lain sectio caesaria, persalinan vakum, persalinan sunsang, dan persalinan dengan induksi. Pada penelitian ini, persalinan dengan tindakan yang paling sering dilakukan adalah sectio caesaria. Persalinan dengan sectio caesaria berisiko infeksi 80 kali lebih tinggi daripada persalinan pervaginam. ${ }^{20}$ Persalinan dengan tindakan juga dapat menyebabkan kematian pada bayi yang dilahirkan. Penelitian di RSUD dr. M Soewandhie Surabaya menyimpulkan bahwa 73\% bayi dengan persalinan tindakan mengalami asfiksia neonatus dengan tingkat risiko asfiksia 5,471 kali. ${ }^{21}$

Keterlambatan rujukan juga terbukti secara signifikan berhubungan dengan kematian ibu $(O R=10$; nilai $p=$
0,013, CI 95\% = 1,34-74,5). Penelitian sebelumnya, di Kabupaten Cilacap, faktor keterlembatan terutama keterlambatan mengambil keputusan untuk merujuk dan keterlambatan mencapai tempat rujukan berhubungan dengan kematian ibu. ${ }^{22}$ Pada penelitian ini, kelompok kasus mengalami lebih dari satu jenis keterlambatan dan yang palin banyak adalah keterlambatan memutuskan dan membawa ibu ke fasilitas kesehatan. Akibat keengganan ibu untuk segera menuju fasilitas kesehatan karena menganggap tanda komplikasi yang dialami biasa terjadi dalam kehamilan, sementara anggota keluarga lain tidak mengetahui berbagai tanda kegawatan pada komplikasi obstetrik. Pada umumnya hal tersebut terjadi pada ibu dengan paritas $>1$ karena merasa berpengalaman pada kehamilan sebelumnya.

\section{Determinan Jauh}

Faktor nonmedis yang mempengaruhi kematian ibu secara tidak langsung adalah kondisi ekonomi, sosial, dan budaya di lingkungan tempat tinggal ibu hamil. Pada penelitian ini, determinan jauh yang meliputi tingkat pendidikan, status pekerjaan, dan pendapatan keluarga tidak berhubungan dengan kematian ibu. Hasil tersebut berbeda dengan hasil penelitian sebelumnya di Provinsi Nusa Tenggara dimana faktor sosial ekonomi dan demografi, seperti kemiskinan, tingkat pendidikan yang rendah, budaya, bias gender dalam masyarakat, dan keluarga serta lokasi tempat tinggal yang terpencil menyebabkan AKI yang tinggi di daerah tersebut. ${ }^{23}$

Persebaran kematian ibu di Kabupaten Pati menunjukkan bahwa jumlah kematian ibu terbanyak tidak terjadi di kecamatan dengan persentase kemiskinan tertinggi. Hal tersebut mengindikasikan bahwa kemiskinan bukan faktor penyebab kematian ibu di Kabupaten Pati. Program Jaminan Persalinan (Jampersal) menyebabkan akses pemeriksaan kehamilan dan persalinan di tenaga kesehatan terbuka bagi keluarga miskin. Wawancara dengan bidan desa, bidan puskesmas dan ketua bidang Pelayanan Kesehatan Dinas Kesehatan Kabupaten Pati menyatakan bahwa Jampersal di Kabupaten Pati telah berjalan baik. Sebagian besar ibu hamil telah memanfaatkan program tersebut yang dibuktikan dengan semakin meningkatkan jumlah persalinan tenaga kesehatan.

\section{Kesimpulan}

Tiga penyebab utama kematian ibu di Kabupaten Pati Tahun 2011 adalah penyakit jantung, preeklamsi/eklamsi, dan perdarahan. Pada tahun tersebut, kematian tersebar di 16 Kecamatan dengan jumlah kematian terbanyak adalah Kecamatan Tlogowungu dan Sukolilo. Berdasarkan waktu meninggal, kematian terbanyak terjadi pada masa nifas. Penyebab kematian ibu di Kabupaten Pati tahun 2011 adalah komplikasi kehamilan (OR 
$=12,198$, nilai $\mathrm{p}=0,010)$, komplikasi persalinan $(\mathrm{OR}=$ $9,94$, nilai $\mathrm{p}=0,020)$, dan riwayat penyakit $(\mathrm{OR}=$ $27,735$, nilai $\mathrm{p}=0,011)$. Secara bersama-sama, ketiga variabel tersebut memberikan pengaruh sebesar 64,3\% terhadap kematian ibu di Kabupaten Pati tahun 2011, sedangkan $35,7 \%$ dipengaruhi oleh variabel-variabel lain.

\section{Saran}

Untuk menurunkan AKI di Kabupaten Pati perlu dilakukan deteksi dini faktor risiko dan potensi komplikasi obstetrik terutama komplikasi kehamilan dan persalinan agar dapat dilakukan upaya pencegahan secara optimal. Untuk itu perlu dilakukan peningkatkan kualitas pelayanan antenatal dan postnatal diantaranya dengan meningkatkan kualitas tenaga kesehatan dengan pembekalan keterampilan teknis dan nonteknis terutama kepada para bidan yang bertugas di desa. Selain itu, perlu adanya keterlibatan keluarga terutama suami dan atau anggota keluarga lain yang tinggal serumah dengan ibu hamil dalam mengawasi ibu hamil dengan faktor risiko melalui pemberian informasi dan pengetahuan tentang risiko kehamilan dan tanda kegawatan obsetrik agar ketika terjadi komplikasi obstetrik dapat segera dikenali sehingga mendapatkan penanganan dengan segera.

\section{Daftar Pustaka}

1. World Health Organization. Trends in maternal mortality: 1999 to 2008. Geneva: World Health Organization press; 2010.

2. Herawati I. Analisis kematian ibu di Indonesia tahun 2010 berdasarkan data SDKI, Riskesdas, dan laporan rutin kesehatan ibu dan anak. Pertemuan Teknis Kesehatan Ibu; 6 April 2011; Bandung, Indonesia. Jakarta: Departemen Kesehatan Republik Indonesia; 2011.

3. McCharty J, Maine DA. Framework for analysis the determinants of maternal Mortality. Studies in Family Planing. 1992; 23 (1): 23-33.

4. Kementerian Negara Pemberdayaan Perempuan. Angka kematian ibu melahirkan. Jakarta: 2011 [diakses tanggal 15 Februari 2013]. Diunduh dalam:http://www.menegpp. go.id/V2/index.php/datadaninformasi/kesehatan

5. Hernandez-Correa JC. Maternal mortality and risk factors at the community level. Economic Working Paper. Departement of Economics. Michigan: Western Michigan University; 2010.

6. Gemari. Peran ibu sangat besar bangun karakter bangsa [online]. 2009; 95 [diakses tanggal 3 Desember 2012]. Diunduh dalam: www.gemari.or.id/artikel/3852.shtml. 2008

7. Kompasiana. Angka kematian ibu di Jawa Tengah Masih Tinggi 2012 [diakses tanggal 3 Januari 2013]. Diunduh dalam: http://health.kompas.com/read/2012/12/27/09261769. 01/03/2013.

8. Anonim. Upaya penurunan kematian ibu/BBL di rumah sakit. 2012 [diakses tanggal 20 Juli 2012]. Diunduh dalam: http://id.scribd.com/-
doc/87322569/AKI-rakontek. 07/18/2012.

9. Suryawati C. Faktor sosial budaya dalam praktik perawatan kehamilan, persalinan, dan pasca persalinan (Studi di Kecamatan Bangsri Kabupaten Jepara). Jurnal Promosi Kesehatan Indonesia. 2007; 2 (1): 21-31.

10. Aeni N. Perilaku kesehatan ibu hamil di Kabupaten Pati (Studi pada kasus kematian maternal tahun 2011). Jurnal Litbang. 2012; 8 (3): 200-7

11. Fibriani A I. Faktor-faktor risiko yang mempengaruhi kematian maternal (Studi kasus di Kabupaten Cilacap) [tesis]. Semarang: Universitas Diponegoro; 2007.

12. Bazaar A, Theodorus A, Azhari. Maternal mortality and contributing risk factors. Indonesian Journal of Obstetric and Gynecology. 2012; 36 (1): 8-13.

13. Manuaba IA, Manuaba IBGF., Manuaba, IBG. Mamahami kesehatan reproduksi wanita. Jakarta: Penerbit Buku Kedokteran EGC; 2002.

14. Lamminpää R, Vehviläinen-Julkunen K, Gissler MH. Preeclampsia complicated by advanced maternal age: a registry-based study on primiparous women in Finland 1997-2008. BMC Pregnancy Childbirth [serial on the internet]. 2012; 12 (47) [cited 2012 Dec 10]. Available from: www.biomedcentral.com/1471-2393/47.

15. Fransisca SK. Perdarahan post partum [diakses tanggal 21 Agustus 2012]. Diunduh dari: http://last3arthtree.wordpress.com/page/2/. 2007.03/22/2012.

16. Drenthen W, Boersma E, Balci A, Moons P, Ross-Hesselink JW, Mulder BJ, et al. Predictors of pregnancy complications in women with congenital heart disease. Eur Heart J [serial on the internet]. 2010; 31: 212432 [cited 2012 Mar 15]. Available from: http://eurheartj.oxfordjournals.org.

17. Noor HM. Analisis faktor risiko terhadap kematian maternal di Kabupaten Bulukumba Tahun 2007-2009. Jurnal Media Kebidanan Poltekkes Makassar. 2010; 2 (2); 47-55.

18. Retnaningsih E. Studi kasus kontrol: pengaruh faktor perilaku layanan kesehatan ibu hamil terhadap kematian ibu di empat kabupaten/kota di Provinsi Sumetera Utara. Buletin Penelitian Kesehatan. 2009; 37 (2): 67-78.

19. Suparman. Antenatal care dan kematian maternal. Jurnal Penduduk dan Pembangunan. 2007; 7 (1); 7-14

20. Sadiman, Ridwan M. Faktor-faktor yang berhubungan dengan persalinan seksio caesarea di RSUD Ahmad Yani Metro Tahun 2008. Jurnal Kesehatan "Metro Sai Wawai". 2009; 11 (2): 1-10.

21. Sitepu NY. Hubungan antara jenis persalinan dengan kejadian asfiksia neonatum di RSUD dr. M Soewandhie Surabaya [skripsi]. Surabaya: Universitas Airlangga; 2011.

22. Fibriani AI, Azam M. Three delay model sebagai salah satu determinan kematian ibu di Kabupaten Cilacap. Kemas [online]. 2010; 6 (10): 1623 [diakses tanggal 10 Januari 2012]. Diunduh dari: http//journal.unnes.ac.id/index.php/kemas.

23. Sinaga M. Beberapa faktor sosial demografi yang berhubungan dengan tingginya angka kematian ibu di Provinsi Nusa Tenggara Timur. Majalah Kedokteran Muhammadiyah. 2007; 3 (2): 85-9. 